\title{
Cell cycle inhibition reduces inflammatory responses, neuronal loss, and cognitive deficits induced by hypobaria exposure following traumatic brain injury
}

Jacob W. Skovira ${ }^{1,2+}$, Junfang Wu ${ }^{1 *+} \mathbb{D}$, Jessica J. Matyas ${ }^{1}$, Alok Kumar ${ }^{1}$, Marie Hanscom ${ }^{1}$, Shruti V. Kabadi ${ }^{1}$, Raymond Fang ${ }^{3}$ and Alan I. Faden ${ }^{1 *}$

\begin{abstract}
Background: Traumatic brain injury (TBI) patients in military settings can be exposed to prolonged periods of hypobaria (HB) during aeromedical evacuation. Hypobaric exposure, even with supplemental oxygen to prevent hypoxia, worsens outcome after experimental TBI, in part by increasing neuroinflammation. Cell cycle activation (CCA) after TBI has been implicated as a mechanism contributing to both post-traumatic cell death and neuroinflammation. Here, we examined whether hypobaric exposure in rats subjected to TBI increases CCA and microglial activation in the brain, as compared to TBI alone, and to evaluate the ability of a cyclin-dependent kinase (CDK) inhibitor (CR8) to reduce such changes and improve behavioral outcomes.
\end{abstract}

Methods: Adult male Sprague Dawley rats were subjected to fluid percussion-induced injury, and HB exposure was performed at $6 \mathrm{~h}$ after TBI. Western blot and immunohistochemistry $(\mathrm{IHC})$ were used to assess cell cycle-related protein expression and inflammation at 1 and 30 days after injury. CR8 was administered intraperitoneally at $3 \mathrm{~h}$ post-injury; chronic functional recovery and histological changes were assessed.

Results: Post-traumatic hypobaric exposure increased upregulation of cell cycle-related proteins (cyclin D1, proliferating cell nuclear antigen, and (DK4) and microglial/macrophage activation in the ipsilateral cortex at day 1 post-injury as compared to TBI alone. Increased immunoreactivity of cell cycle proteins, as well as numbers of Iba- $1^{+}$and $\mathrm{GFAP}^{+}$cells in both the ipsilateral cortex and hippocampus were found at day 30 post-injury. TBI/HB significantly increased the numbers of NADPH oxidase 2 ( $\left(\mathrm{gp} 1^{\text {phox }}\right.$ ) enzyme-expressing cells that were co-localized with Iba- $1^{+}$. Each of these changes was significantly reduced by the administration of CR8. Unbiased stereological assessment showed significantly decreased numbers of microglia displaying the highly activated phenotype in the ipsilateral cortex of TBI/HB/CR8 rats compared with TBI/HB/Neh rats. Moreover, treatment with this CDK inhibitor also significantly improved spatial and retention memory and reduced lesion volume and hippocampal neuronal cell loss.

Conclusions: HB exposure following TBI increases CCA, neuroinflammation, and associated neuronal cell loss. These changes and post-traumatic cognitive deficits are reduced by CDK inhibition; such drugs may therefore serve to protect TBI patients requiring aeromedical evacuation.

Keywords: Traumatic brain injury, Inflammation, Neuronal cell death, Aeromedical evacuation, Hypobaria

\footnotetext{
* Correspondence: jwu@anes.umm.edu; afaden@anes.umm.edu

${ }^{\dagger}$ Equal contributors

'Department of Anesthesiology and Center for Shock, Trauma and

Anesthesiology Research (STAR), University of Maryland School of Medicine,

Baltimore, MD 21201, USA

Full list of author information is available at the end of the article
} 


\section{Background}

Traumatic brain injury (TBI) is a major cause of morbidity and mortality in civilian populations [1] and has been a serious concern for US military forces, where the number of cases has nearly tripled over the last decade [2]. TBI casualties are moved from the battlefield to the appropriate level of care through the military aeromedical evacuation (AE) system [3]. During transport, patients can be exposed to long periods of hypobaria (HB), as military flights are often pressurized only to $8000 \mathrm{ft}$, substantially different from commercial air travel $[3,4]$. It has been recently shown in a rat TBI model that hypobaria during simulated AE worsens cognitive and pathological outcomes [5]; this report and an earlier one using a mouse TBI model also suggest that hypobaria can increase posttraumatic inflammatory responses [6].

TBI-related neuropathology reflects both direct mechanical damage (primary injury) and delayed induced molecular and cellular cascades (secondary injury)-leading to neuronal cell death, axonal disruption, demyelination, astrogliosis, and inflammation [7]. Cell cycle activation (CCA) occurs after TBI in both neurons and glial cells and contributes to secondary injury [8-10]. In postmitotic cells such as neurons, CCA contributes to programmed cell death. In glia, CCA induces astrocyte and microglial proliferation/reactivation, leading to astroglial scar formation, release of pro-inflammatory cytokines and reactive oxygen species (ROS), and ultimately neuronal degeneration [8-10]. Administration of cell cycle inhibitors after TBI increases neuronal survival and reduces both microglial and astroglial activation; the latter includes multiple studies utilizing the rat LFP injury model [11-15].

TBI-induced neuroinflammation appears to play a pivotal role in secondary injury severity and progression. Although the neuroinflammatory response to injury may have either beneficial or detrimental actions [16], both pre-clinical and clinical studies show that chronic microglial activation after TBI contributes to both progressive neurodegeneration and related neurological deficits [17-19]. As sustained posttraumatic CCA appears to contribute to chronic neuroinflammation, this study was designed to evaluate whether $\mathrm{HB}$ following TBI increases both CCA and related neuroinflammation and whether CCA inhibition can limit these harmful consequences of hypobaric exposure and reduce cognitive dysfunction.

\section{Methods}

\section{Animals}

Male Sprague Dawley rats (Harlan Labs, Frederick, MD) weighing $325 \mathrm{~g}$ ( $\pm 25 \mathrm{~g}$ ) were utilized for this study. Animals were fed a standard laboratory diet with food and water ad libitum. All procedures and experiments were carried out in accordance with protocols approved by the Animal Care and Use Committee at the University of Maryland and the United States Air Force.

\section{Micro-fluid percussion and hypobaric animal experiments} Rats were anesthetized with isoflurane (4\% induction, 2\% maintenance), and a 5-mm craniotomy was made over the left parietal cortex midway between the lambda and bregma as previously described $[5,20]$. Using our custom micro-fluid percussion (FP) device, a 1.5-1.9-atmosphere (atm) pressure was used to produce a mild injury with regard to neurologic and histologic deficits [20]. Sham animals underwent the same procedures without injury. Hypobaria was induced using a steel cylindrical chamber with interior dimensions of $46 \mathrm{~cm}$ wide and $112 \mathrm{~cm}$ long equipped with internal temperature, oxygen, carbon dioxide, and pressure gauges and connected to a vacuum pump. Animals were placed into the chamber in their home cages with access to water and food to reduce stress from acclimation to the HB chamber. Multiple animals in various groups were randomly exposed simultaneously. The chamber was de-pressurized over $30 \mathrm{~min}$ to reach $568 \mathrm{mmHg}$ (=8000 ft. altitude) - approximating the cabin pressure during military $\mathrm{AE}$ with cruising altitudes of $30,000-40,000 \mathrm{ft}$. To account for the mean oxygen saturation decrease of $5.5 \%$ experienced at this pressure, $28 \%$ $\mathrm{O}_{2}$ was continuously delivered to the chamber to maintain $\mathrm{pO}_{2}$ at sea level despite the drop in atmospheric pressure. Chamber gases were continuously monitored to validate concentration of $\mathrm{O}_{2}$ delivered, as well as to verify that $\mathrm{CO}_{2}$ was not accumulating in the chamber. At $5.5 \mathrm{~h}$ of "flight," the chamber was re-pressurized over $30 \mathrm{~min}$ to $1 \mathrm{~atm}(765 \mathrm{mmHg})$, and the animals were then removed. Interior chamber temperature was monitored continuously and maintained at $22 \pm 2{ }^{\circ} \mathrm{C}$.

\section{Experimental procedure}

An inhibitor of cell cycle activation-(2-(R)-(1-ethyl-2hydroxyethylamino)-6-(4-(2-pyridyl)benzyl)-9-isopropyl-

purine trihydrochloride (CR8, Tocris Bioscience, Minneapolis, MN), was evaluated for its effects on cellular inflammatory reactions (microglial and astrocyte activation) as well as on histologic and neurologic outcome after TBI. For tissue collection experiments, male rats were randomized to one of four groups: sham injury, TBI alone, $\mathrm{TBI}+\mathrm{HB}+$ vehicle (Veh), and $\mathrm{TBI}+\mathrm{HB}+\mathrm{CR} 8$ (Fig. 1). For behavioral analysis and stereology experiments, male rats were randomized to one of three groups: sham injury, TBI + HB + Veh, and TBI + HB + CR8 (Fig. 1). We have previously reported a TBI-alone group for behavioral analysis [5]. Animals in the treatment groups received a dose of CR8 (5 mg/kg in saline, IP) or an equal volume of vehicle (saline) $3 \mathrm{~h}$ following the induction of a TBI. Six hours after the induction of TBI (1.5-1.9 atm), the animals were exposed to $\mathrm{HB}$ for $6 \mathrm{~h}$ at $0.75 \mathrm{~atm}$. This 


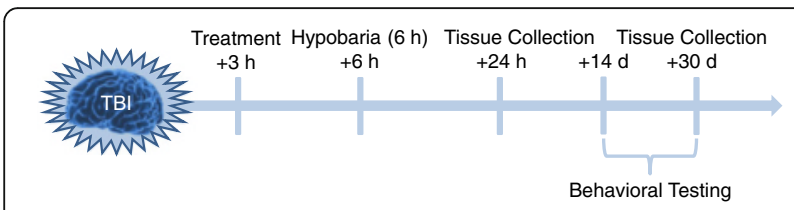

Fig. 1 Experimental timeline for evaluating CR8 treatment on simulated AE-induced cell cycle activation and inflammatory responses following TBI

dose and timing of administration was based on previous studies using this compound in experimental animal models of TBI-which have shown neuroprotection by limiting microglial activation, astrocytosis, and neuronal loss $[5,15]$. Behavioral tests were conducted over 30 days post-HB. This experimental timeline was chosen to be consistent and comparable to established procedures for accurate assessment of behavioral and histological outcomes following TBI $[5,15]$. All behavioral tests were conducted by an experimenter blinded to the experimental groups. Behavioral testing included Morris water maze tests for learning and memory (post-HB days 14-18), novel object recognition test for retention memory (postHB day 21), and the forced swim test (post-HB day 26) for depressive-like behaviors. Brains were collected at $24 \mathrm{~h}$ post-injury or on post-HB day 30 for pathologic or immunohistochemical analysis. The number of rats in each group or subgroup is indicated in Table 1.

\section{Tissue collection and western blot}

At $24 \mathrm{~h}$ post-injury, rats were anesthetized with sodium pentobarbital $(100 \mathrm{mg} / \mathrm{kg}$, IP). A blunt 21 -gauge needle connected to a peristaltic pump (Harvard Apparatus, Holliston, MA) primed with $0.9 \%$ sodium chloride (saline) was pierced through the left lateral ventricle and inserted diagonally into the ascending aorta. An incision

Table 1 Definition of the groups

\begin{tabular}{lll}
\hline Groups/rats \# & $\begin{array}{l}\text { Functional } \\
\text { assessment }\end{array}$ & $\begin{array}{l}\text { Outcome measures in subgroups } \\
\text { (subgroups, randomly selected) }\end{array}$ \\
\hline $\begin{array}{l}\text { 24 h TBI } \\
\text { Sham }\end{array}$ & 7 & WB \\
TBI & 9 & WB \\
TBI/Neh/HB & 10 & WB \\
TBI/CR8/HB & 7 & WB \\
30 days TBI & 16 & \\
Sham & 6 & Behavioral tests, IHC \\
TBI & 14 & $\begin{array}{l}\text { IHC } \\
\text { TBI/Neh/HB }\end{array}$ \\
TBI/CR8/HB & 15 & $\begin{array}{l}\text { Behavioral tests, IHC, lesion } \\
\text { volume, stereology } \\
\text { Behavioral tests, IHC, lesion } \\
\text { volume, stereology }\end{array}$ \\
\hline
\end{tabular}

$T B I$ traumatic brain injury, $W B$ western blot, $H B$ hypobaria, Veh vehicle, IHC immunohistochemistry was then made in the right atrium to allow the fluid to flow through. The brain was perfused with saline at a rate of $50 \mathrm{ml} / \mathrm{min}$ for $10 \mathrm{~min}$ before being removed. A 5 - $\mathrm{mm}$ area surrounding the lesion epicenter on the ipsilateral cortex was rapidly dissected placed in a $1-\mathrm{ml}$ microcentrifuge tube and flash frozen with liquid nitrogen. Frozen tissue samples were stored at $-80{ }^{\circ} \mathrm{C}$ prior to analysis.

For all immunoblot samples, the cortical tissue was homogenized in radioimmunoprecipitation assay (RIPA) buffer and centrifuged at $15,000 \mathrm{rpm}$ for $15 \mathrm{~min}$ at $4{ }^{\circ} \mathrm{C}$ to isolate proteins, and the protein concentration was determined using the Pierce BCA Protein Assay kit (Thermo Scientific, Rockford, IL). Twenty-five microgram of protein was run on sodium dodecyl sulfate (SDS) polyacrylamide gel electrophoresis and transferred onto nitrocellulose membrane ( $n=6-10 /$ group). The blots were probed with antibodies against cyclin-dependent kinase (CDK)4 (1:1000, Santa Cruz Biotechnology, Inc., Santa Cruz, CA); cyclin D1 (1:500, Santa Cruz Biotechnology, Inc., Santa Cruz, CA); proliferating cell nuclear antigen (PCNA; 1:500, Santa Cruz Biotechnology); and ionized calcium-binding adapter molecule 1 (Iba-1; 1:1000, Wako Chemicals, Richmond, VA), and GAPDH (1:2000; SigmaAldrich, St. Louis, MO) was used as an endogenous control. Immune complexes were detected with the appropriate horseradish peroxidase (HRP)-conjugated secondary antibodies (KPL, Inc., Gaithersburg, MD) and visualized using SuperSignal West Dura Extended Duration Substrate (Thermo Scientific, Rockford, IL). Chemiluminescence was captured on a Kodak Image Station 4000R station (Carestream Health, Rochester, NY), and protein bands were quantified by densitometric analysis using Carestream Molecular Imaging Software. The data presented reflect the intensity of the target protein band compared to the control and were normalized based on the intensity of the endogenous control for each sample.

\section{Functional assessment Morris water maze}

Spatial learning and memory were assessed using the acquisition paradigm of the Morris water maze (MWM) test as previously described [15]. A circular pool (1.5 m in diameter) was divided into four quadrants using computer-based AnyMaze video tracking system (Stoelting Co., Wood Dale, IL). Each rat was subjected to four trials to locate the hidden platform every day from postHB days 14 to 17 (acquisition phase). Latency (seconds) to locate the hidden platform was measured, with a 90-s limit per trial, and swimming velocities assessed. Water maze search strategy analysis was also performed as previously described [15]. Reference memory was assessed by a probe trial carried out on post-HB day 18. A visual cue test was also performed on post-HB day 18 . 


\section{Novel object recognition}

Nonspatial retention and recognition memory was assessed by the novel object recognition test as previously described $[5,15]$. On post-HB day 20 , animals were placed into the open field and allowed to explore for 10 min each without any of the objects present for habituation and familiarization. On the testing day (post-HB day 21), two trials of $5 \mathrm{~min}$ each were performed. The first trial (training phase) involved placing identical square-shaped "old objects" in both zones of the open field. The second trial (testing phase) involved placing one square-shaped "old object" and one triangularshaped "novel object" in the respective zones of the open field. The time that was spent exploring each object during both trials was recorded. In addition, time spent in the novel object and old object zones was analyzed and compared between groups separately. The cognitive outcomes were calculated as the "discrimination index" (D.I.) for the second trial using the following formula: \% D.I. = (time spent exploring novel object / (total time spent exploring both objects) $) \times 100$.

\section{Forced swim test}

The forced swim test was used to examine depressivelike behaviors $[5,15]$. On post-HB day 26 , rats were individually forced to swim inside a vertical plastic container (height $60 \mathrm{~cm}$; diameter $25 \mathrm{~cm}$ ) containing $30 \mathrm{~cm}$ of water for a time period of $6 \mathrm{~min}$. The total duration of immobility (passive floating, slightly hunched, upright position, the head just above the surface) vs. struggle (diving, jumping, strongly moving all four limbs, scratching the walls) was recorded.

\section{Tissue processing, immunohistochemistry, image acquisition, and quantification}

At 30 days after injury, rats were anesthetized and intracardially perfused with $200 \mathrm{ml}$ of saline followed by $300 \mathrm{ml}$ of $4 \%$ paraformaldehyde. The dissected brains were post-fixed for overnight and cryoprotected through a sucrose gradient. The coronal sections were cut, serially collected $(3 \times 60 \mu \mathrm{m}$ followed by $3 \times 20 \mu \mathrm{m}$ sections) throughout the brain and mounted onto glass slides for histology and immunohistochemistry.

Standard fluorescent immunohistochemistry on serial, $20-\mu \mathrm{m}$-thick sections was performed as described previously [21]. The following primary antibodies were used: rabbit anti-CDK4 (1:500, Santa Cruz Biotechnology); mouse anti-cyclin D1 (1:500, Neomarker); rabbit antiPCNA (1:500, Santa Cruz Biotechnology); rabbit or mouse anti-GFAP (1:1000, Chemicon); rabbit anti-Iba-1 (1:1000, Wako Chemicals); mouse anti-gp91 ${ }^{\text {phox }}$ (1:500; BD Transduction Laboratories, Franklin Lakes, NJ); and galectin 3 (1:500, Santa Cruz Biotechnology).
Fluorescent-conjugated secondary antibodies (1:1000, Alexa 488-conjugated goat anti-mouse or rabbit, Alexa Fluor 546 goat anti-mouse, Alexa Fluor 633 goat antimouse, Molecular Probes) were incubated with tissue sections for $1 \mathrm{~h}$ at room temperature. Counterstaining was performed with 4',6-diamidino-2-phenylindole (DAPI) $(1 \mu \mathrm{g} / \mathrm{ml}$; Sigma-Aldrich). All immunohistological staining experiments were carried out with appropriate positive control tissue as well as primary/secondary-only negative controls.

For quantitative image analysis, images were acquired using a fluorescent Nikon Ti-E inverted microscope, at $\times 20$ (CFI Plan APO VC 20× NA 0.75 WD 1 mm) magnification. Exposure times were kept constant for all sections in each experiment. Background for all images was subtracted using Elements. All images were quantified using Elements: nuclei were identified using Spot Detection algorithm based on DAPI staining; cells positive for any of the immunofluorescence markers were identified using Detect Regional Maxima or Detect Peaks algorithms, followed by global thresholding. The intensity of cyclin D1, PCNA, and CDK4 was normalized to the total area imaged. The number of positive cells was normalized to the total number of cells based on DAPI staining. All quantifications were performed in the ipsilateral cortex and hippocampus. For each experiment, data from all images from one region in each animal were summated and used for statistical analysis [22, 23]. At least 1000-2000 cells were quantified for each rat per area per experiment.

\section{Stereological quantification of microglial phenotypes in the ipsilateral cortex}

Every fourth $60-\mu \mathrm{m}$ brain section was immunostained for Iba-1 and DAB and analyzed using a Leica DM4000B microscope (Leica Micro-systems Inc., Buffalo Grove, IL, USA). The number of cortical microglia in either activated (hypertrophic and bushy) or resting (ramified) morphologic phenotypes were counted using the optical fractionator method with the Stereo Investigator software (MBF Biosciences) as described previously [5, 15]. Microglial phenotypic classification was based on the length and thickness of the projections, the number of branches, and the size of the cell body, as previously described [5]. The sampling region was between -2.04 and $-4.56 \mathrm{~mm}$ from the bregma in the ipsilateral cortex with a dorsal depth of $2.0 \mathrm{~mm}$ from the surface. The volume of the region of interest was measured using the Cavalieri estimator method. The estimated number of microglia in each phenotypic class was divided by the volume of the region of interest to obtain cellular density expressed in counts per cubic millimeters $\left(\mathrm{mm}^{3}\right)$. 
Lesion volume and neuronal survival in the hippocampal subregions

Sections were stained with cresyl violet (FD NeuroTechnologies, Baltimore, MD), dehydrated, and mounted for analysis. Lesion volume was quantified based on the Cavalieri method of unbiased stereology using Stereologer 2000 program software (Systems Planning and Analysis, Alexandria, VA). The lesion volume was quantified by outlining the missing tissue on the injured hemisphere using the Cavalieri estimator with a grid spacing of $0.1 \mathrm{~mm}$. Every fourth $60-\mu \mathrm{m}$ section between -2.04 and $-4.56 \mathrm{~mm}$ from the bregma was analyzed beginning from a random start point.

The total number of surviving neurons in the cornus ammonis (CA)1, CA2, CA3, and dentate gyrus (DG) subregions of the hippocampus was assessed using the optical fractionator method $[5,15]$. Every fourth $60-\mu \mathrm{m}$ section between -2.04 and $-4.56 \mathrm{~mm}$ from the bregma was analyzed, beginning from a random start point. The volume of each hippocampal subfield was measured using the Cavalieri estimator method. The estimated number of surviving neurons in each field was divided by the volume of the region of interest to obtain the neuronal cellular density, expressed as counts $/ \mathrm{mm}^{3}$.

\section{Statistical analysis}

Quantitative data were expressed as mean \pm standard error of the mean (SEM). Analysis of histological data was conducted using a one-way ANOVA followed by the Student-Newman-Keuls post hoc test. Functional data (latency to find the platform in seconds) for the acquisition phase of the MWM were analyzed by repeated measure (trial over time) two-way ANOVA (TBI + $\mathrm{Veh}+\mathrm{HB}$ vs. $\mathrm{TBI}+\mathrm{CR} 8+\mathrm{HB}$ ) to determine the interactions of post-injury days and groups, followed by post hoc adjustments using the Student-Newman-Keuls test. As we are only interested in whether CR8 treatment improves outcomes over TBI + HB with vehicle treatment, further analysis of behavioral outcomes was conducted using a one-tailed unpaired Student's $t$ test to determine the differences between groups within each trial day. The comparison of search strategies during the final day of the trials of the MWM acquisition phase was analyzed using a chi-square test. As we are only interested in whether CR8 treatment improves outcomes over $\mathrm{TBI}+\mathrm{HB}$ with vehicle treatment, all other analyses (MWM probe, novel object, forced swim, stereological assessments, lesion volume) were conducted using a one-tailed unpaired Student's $t$ test (TBI + Veh + HB vs. $\mathrm{TBI}+\mathrm{CR} 8+\mathrm{HB})$. All tests were performed using either SigmaPlot 12 (Systat Software, San Jose, CA) or GraphPad Prism program; version 4.0 (GraphPad Software; San Diego, CA). A $p$ value of less than 0.05 was considered statistically significant.

\section{Results}

\section{Post-traumatic hypobaria exposure increases CCA as} compared to TBI alone

To evaluate the effect of $\mathrm{HB}$ on cell cycle activation, we first examined cell cycle pathway changes in the ipsilateral cortex at day 1 after TBI. Western blotting was performed for the markers of cell cycle-related proteins cyclin D1, PCNA, and CDK4 (Fig. 2). At $24 \mathrm{~h}$ postinjury, a significant increase in the protein expression of these markers was observed in the injured/no-HB exposure group $(n=9)$ in comparison to the sham injury group ( $n=7, p<0.001, \mathrm{TBI} /$ no-HB vs. sham injury). HB exposure following TBI $(n=10)$ significantly further increased the protein expression of cyclin D1, PCNA, and CDK4 in comparison to the TBI/no-HB exposure group ( $p$ $<0.001$ for CDK4, $p<0.05$ for cyclin D1, TBI + HB vs. TBI/ no-HB). In contrast, cell cycle inhibition by administration of CR8 $(n=7)$ limited the TBI + HB-induced increase in the expression of these cell cycle proteins at 1 day postinjury $(p<0.05$ for cyclin D1 and PCNA, $p<0.001$ for $\mathrm{CDK} 4, \mathrm{TBI}+\mathrm{Veh}+\mathrm{HB}$ vs. TBI + CR8 + HB).

We also examined immunoreactivity of cyclin D1, PCNA, and CDK4 in the ipsilateral cortex and hippocampus from sham $(n=4)$, TBI alone $(n=6), \mathrm{TBI}+\mathrm{Veh}+\mathrm{HB}$ $(n=6)$, and $\mathrm{TBI}+\mathrm{CR} 8+\mathrm{HB}(n=6)$ rats at 30 days postinjury. Quantification of pixel intensity for these markers showed significant increases in the $\mathrm{TBI}+\mathrm{Veh}+\mathrm{HB}$ group in contrast to the TBI-alone tissue (Figs. 3, 4, and 5). Cyclin D1 was predominantly expressed by $\mathrm{GFAP}^{+}$astrocytes (Fig. 3d). Most of the $\mathrm{PCNA}^{+}$cells in the injured cortex were co-labeled with galectin 3 -expressing microglia/macrophages (Fig. 4d). Some of the CDK4+ cells displayed neuronal morphology and co-labeled with NeuN (Fig. 5a, d). In addition, CDK4 was also expressed by astrocytes (data not shown). The post-traumatic upregulation of these proteins was attenuated by CR8 treatment.

\section{Cell cycle inhibition reduces microglial activation and astrogliosis induced by hypobaria exposure following TBI}

To examine whether HB-induced activation of microglia and astrocytes were attenuated by inhibiting CCA, rats were treated with CR8 or saline by ip injection at $3 \mathrm{~h}$ post injury and the ipsilateral cerebral cortical tissue was collected at $24 \mathrm{~h}$ after TBI. Quantitative analysis of western blots showed that Iba- 1 expression in TBI $(n=9)$ or TBI + Veh $+\mathrm{HB}(n=10)$ groups increased by approximately 1.5- or 2.1-fold, respectively, as compared to sham-injured animals ( $n=7$, Fig. 6a, b). Notably, CR8 treatment $(n=7)$ significantly attenuated (TBI $+\mathrm{Veh}+\mathrm{HB})$-induced increase of Iba-1 expression. Moreover, immunohistochemical analysis demonstrated that TBI + Veh + HB $(n=6)$, in contrast to TBI-alone tissue $(n=6)$, caused a 1.4-fold of the total number of $\mathrm{Iba}^{+} \mathrm{1}^{+}$microglia/macrophages at 30 days post-injury in both the ipsilateral cortex and 


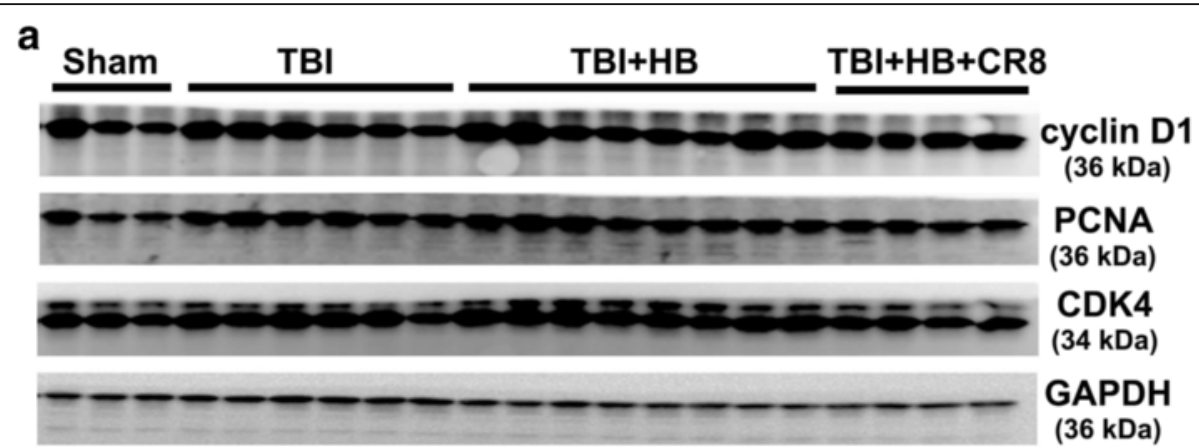

b

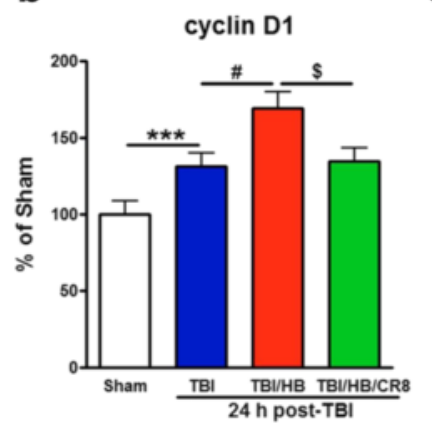

C

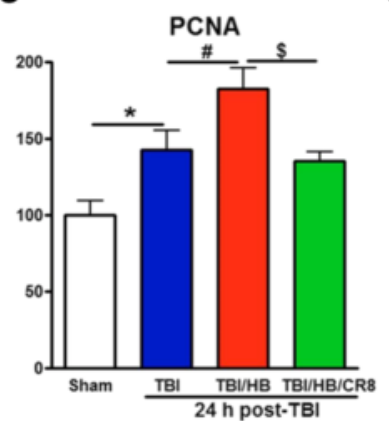

d

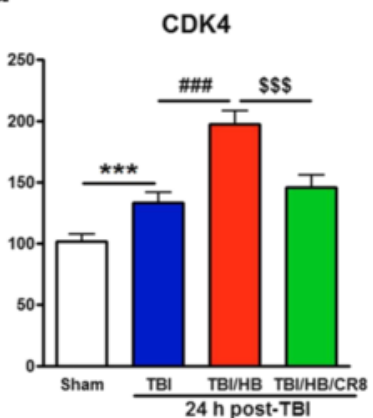

Fig. 2 Hypobaria exposure increases markers of cell cycle activation at $24 \mathrm{~h}$ after TBI. a Representative immunoblots for cell cycle-related proteins (cyclin D1, PCNA, and CDK4) and the loading control (GAPDH). b- $\mathbf{d}$ Expression levels of cell cycle proteins were normalized by GAPDH, as estimated by optical density measurements, and expressed as a percentage of sham tissue. At $24 \mathrm{~h}$ post-injury, a significant increase in the protein expression of cyclin D1, PCNA, and CDK4 was observed in the TBI/no-HB exposure group in comparison to the sham injury group. HB exposure following TBI significantly increased the protein expression of all three markers in comparison to the TBI-alone group. A significant decrease in the protein expression of all three markers was observed in the CR8 treatment group in comparison to the TBINeh/HB group. $N=7$ (sham), 9 (TBI), 10 (TBINeh/HB), 7 (TBI/CR8/HB). ${ }^{*} p<0.05,{ }^{* * *} p<0.001$, TBI vs. sham injury; ${ }^{\#} p<0.05,{ }^{\# \# \#} p<0.001$, TBINeh/HB vs. TBI/no-HB; ${ }^{\$} p<0.05,{ }^{\$ \$ \$} p<0.001$, TBI/CR8/HB vs. TBINeh/HB

hippocampus (Fig. 6c-e). CR8-treated rats $(n=6)$ showed significantly reduced total numbers of Iba- $1^{+}$cells.

It is well known the TBI significantly increases microglial activation [7-15]. In our previous study, we have shown that TBI + HB further increases activated microglia at 30 days in comparison to TBI alone [5]. In order to examine if CR8 treatment reduced the neuroinflammatory response associated with $\mathrm{TBI}+\mathrm{HB}$, stereological quantifications of resting and activated microglia cell numbers in the injured cortex were evaluated at 30 days post-HB. CR8 treatment ( $n=6$, Fig. 7) significantly reduced the total number of microglia and number of activated microglia in comparison to the $\mathrm{TBI}+\mathrm{HB}$ group $(p<0.01, \mathrm{TBI}+\mathrm{CR} 8+\mathrm{HB}$ vs. TBI $+\mathrm{Veh}+\mathrm{HB})$.

In addition, we evaluated the effect of $\mathrm{HB}$ on the expression of NADPH oxidase membrane component gp91 ${ }^{\text {phox }}$ after TBI. Immunohistochemistry at 30 days post-injury demonstrated that TBI + Veh $+\mathrm{HB}(n=6)$ significantly increased the total numbers of gp91 ${ }^{\text {phox }}$-positive cells in contrast to TBI-alone tissue $(n=6$, Fig. $8 \mathrm{a}-\mathrm{c})$. Moreover, double-labeling immunohistochemistry revealed that large numbers of gp91 ${ }^{\text {phox }}$-positive cells in the injured coronal sections were colabeled with Iba-1 (Fig. 8d). Notably, there were fewer gp91 ${ }^{\text {phox }}$-positive cells in the CR8-treated
TBI + HB samples $(n=6)$, and Iba-1 expression was also reduced in these cells.

Quantitative immunofluorescence image analysis also showed significant increases in the total numbers of $\mathrm{GFAP}^{+}$astrocytes in the TBI $+\mathrm{Veh}+\mathrm{HB}$ group $(n=6)$ in contrast to the TBI-alone tissue $(n=6, P<0.01$; Fig. 9). Notably, there were significant reductions in the positively stained cells in both the ipsilateral cortex and hippocampus in CR8-treated animals $(n=6, P<0.01)$.

\section{Cell cycle inhibition by CR8 improves functional outcomes following $\mathrm{TBI}+\mathrm{HB}$}

The MWM was used to evaluate if CR8 treatment attenuates deficits in spatial learning caused by $\mathrm{HB}$ exposure following TBI (Fig. 10a). The factors of "post-injury days" $(F(3126)=102.803 ; \quad p<0.001)$ and "groups" $(F(2126)=12.576 ; p<0.001)$ were found to be significant. The interaction of "post-injury days $\times$ groups" $(F(6126)=7.730 ; p<0.01$; repeated measures two-way ANOVA) was significant. Further analysis of differences between groups for each trial day was conducted using a one-tailed unpaired Student's $t$ test. The TBI + CR8 + HB group showed significant improvement in the spatial learning deficits in comparison to the $\mathrm{TBI}+\mathrm{Veh}+\mathrm{HB}$ 

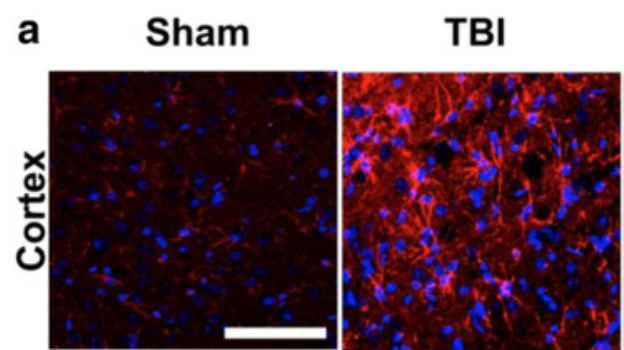

TBI+HB

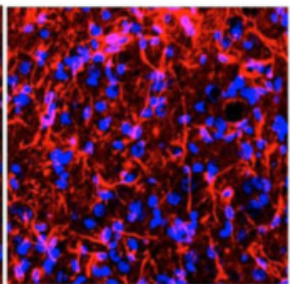

$\mathrm{TBI}+\mathrm{HB}+\mathrm{CR} 8$
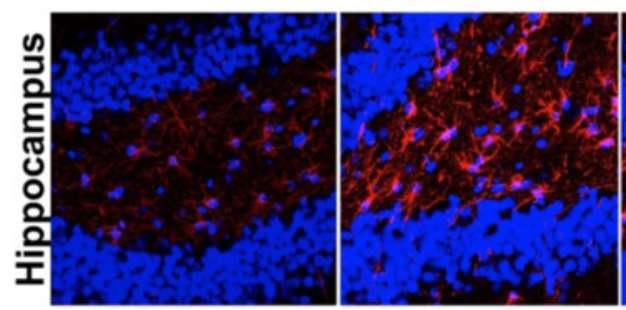

b

Cerebral cortex

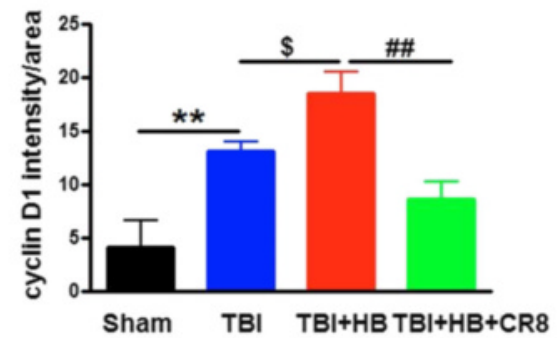

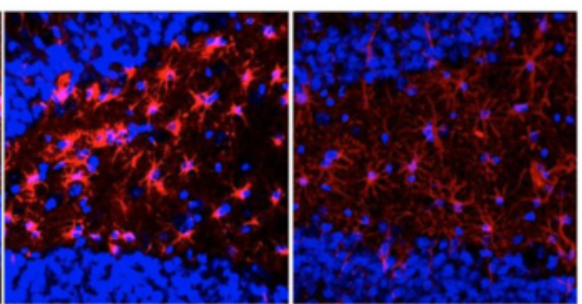

C

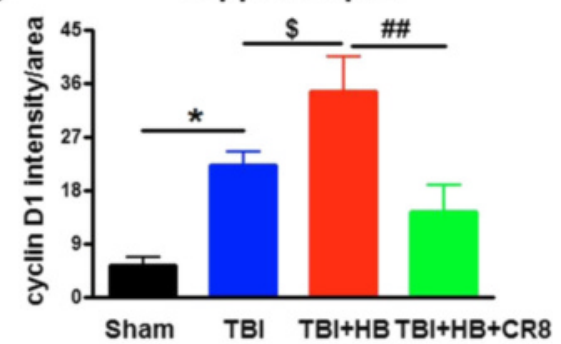

Merged

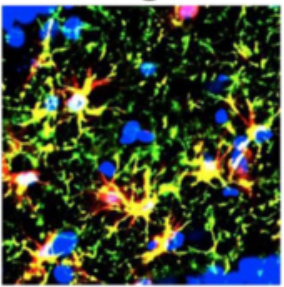

Fig. 3 Hypobaria exposure upregulates the expression of cyclin D1 in the ipsilateral cortex and hippocampus at 30 days after TBI. a Representative immunofluorescent staining for cyclin D1 (red) and DAPI (blue). b, c Quantification of pixel intensity for cyclin D1 revealed significant increases in the TBI + HB group in contrast to the TBl-alone tissue. A significant decrease of cyclin D1 expression was observed in the CR8 treatment group in comparison to the TBI/ Veh/HB group. $N=4$ (sham), 6 (TBI), 6 (TBINeh/HB), 6 (TBI/CR8/HB). ${ }^{*} p<0.05,{ }^{*} p<0.01$, TBI vs. sham injury; ${ }^{\$} p<0.05$, TBINeh/HB vs. TBI; ${ }^{\# \#} p<0.01$, TBI/CR8/HB vs. TBINeh/HB. d Cyclin D1 (red) predominantly expressed by GFAP ${ }^{+}$astrocytes (green; DAPI, blue). Scale bar $=50 \mu \mathrm{m}$ in $\mathbf{a}$ and $\mathbf{d}$

group on trial day 4 (Fig. 10a: $p<0.05$ ). The mean escape latency on the last day of training was $30.2 \pm 3.9 \mathrm{~s}$ for the sham-injured group, $68.6 \pm 6.7$ for the Veh $+\mathrm{HB}$ group, and $51.0 \pm 6.7$ for the CR8-treated group.

The swimming patterns during all trials on the fourth day of the acquisition phase were analyzed to assess the search strategies utilized by the animals to locate the hidden platform (Fig. 10b). A chi-square analysis was used to compare strategies between groups $(p<0.001$; $\left.\chi^{2}=57.79, d f=4\right)$. HB-exposed animals were less efficient in their search strategy while attempting to locate the hidden platform with only $32 \%$ of the day 4 trials reflecting a spatial strategy. CR8-treated animals utilized a spatial search strategy on day 4 in a higher percentage of trials $61 \%$ than untreated injured animals. Spatial memory was assessed using the MWM probe trial on day 18 after HB by examining the number of entries into the target quadrant (Fig. 10c). CR8 treatment increased the number of target quadrant entries in comparison to the $\mathrm{TBI}+\mathrm{Veh}+\mathrm{HB}$ group indicating a reduction in spatial memory deficits in the probe trial $(p<0.05$ vs. Veh $+\mathrm{HB})$. Swim speeds did not differ across groups (Fig. 10d; $p=0.4382$ ).

Nonspatial memory was assessed using the novel object recognition test on post-HB day 21 to evaluate if CR8 treatment improves non-hippocampal-dependent 

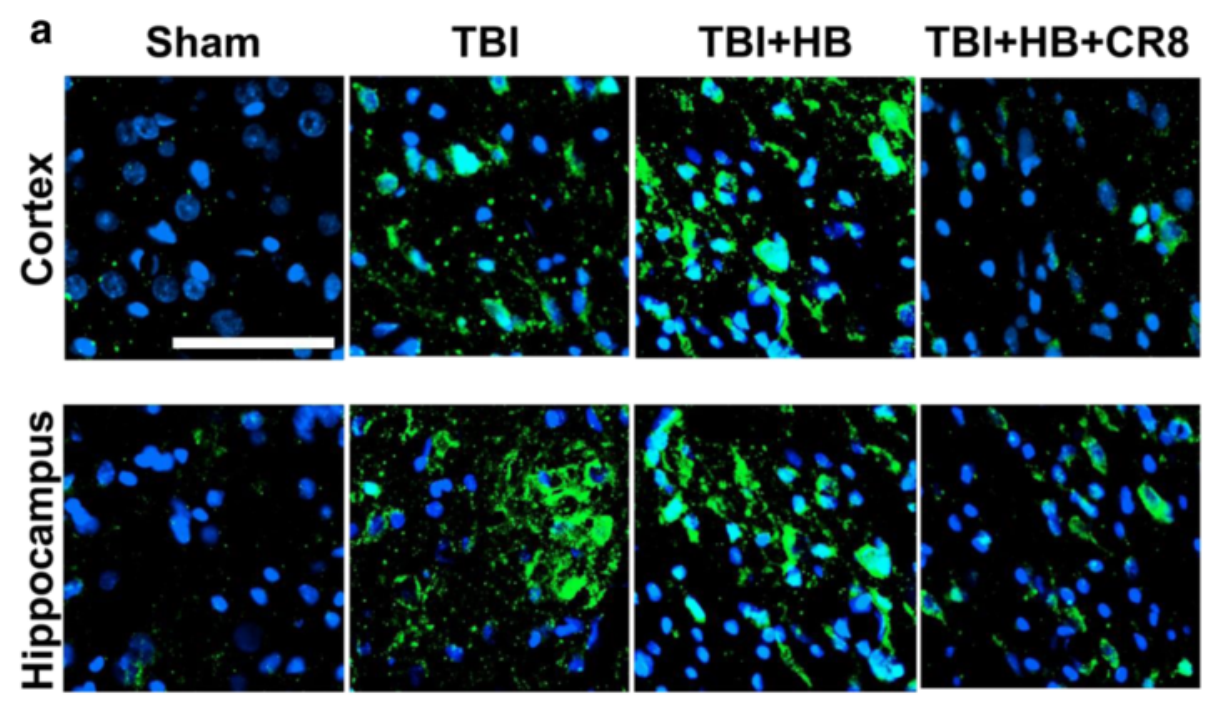

b

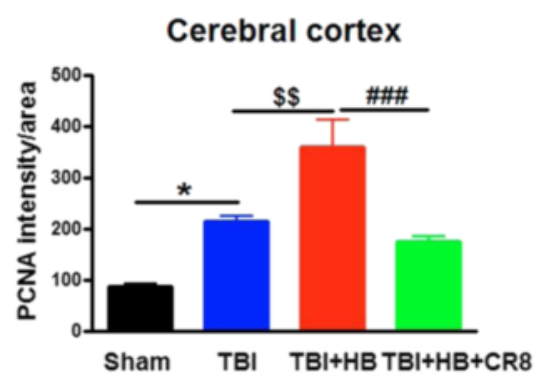

C

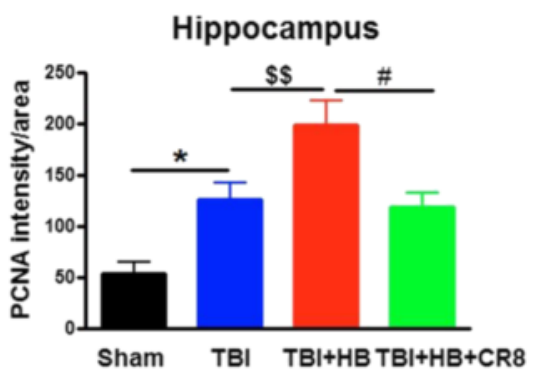

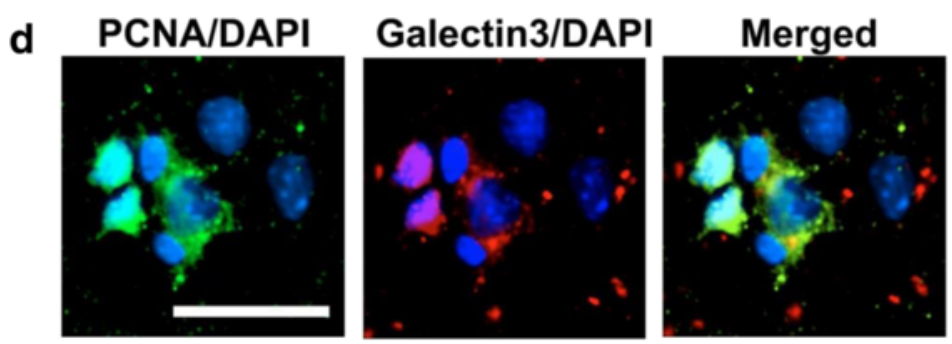

Fig. 4 Hypobaria exposure upregulates the expression of PCNA in the ipsilateral cortex and hippocampus at 30 days after TBI. a Representative immunofluorescent staining for PCNA (green) and DAPI (blue). b, c Quantification of pixel intensity for PCNA revealed significant increases in the $\mathrm{TBI}+$ Veh + HB group in contrast to the TBI-alone tissue. A significant decrease of cyclin D1 expression was observed in the CR8 treatment group in comparison to the TBI/Neh/HB group. $N=4$ (sham), 6 (TBI), 6 (TBINeh/HB), 6 (TBI/CR8/HB). ${ }^{*} p<0.05$, TBI vs. sham injury; ${ }^{\$ \$} p<0.01$, TBINeh/HB vs. TBl; ${ }^{\#} p<0.05, \# \#<0.001, \mathrm{TBI} / \mathrm{CR} 8 / \mathrm{HB}$ vs. TBI/Neh/HB. d Most of the PCNA ${ }^{+}$cells (green) in the injured cortex were co-labeled with galectin 3-expressing microglia/macrophages (red; DAPI, blue). Scale bar $=50 \mu \mathrm{m}$ in $\mathbf{a}$ and $25 \mu \mathrm{m}$ in $\mathbf{d}$

memory (Fig. 10e). Animals showed an equal preference for the two identical objects during the training phase. CR8 treatment significantly increased the discrimination index in comparison to the TBI + vehicle $+\mathrm{HB}$ group indicating an improvement in nonspatial memory $(p<0.01$ vs. TBI + Veh + HB).

The forced swim test was performed on post-HB day 26 to determine if CR8 treatment reduces depressivelike behaviors induced by TBI + HB (Fig. 10f). CR8 treatment did not significantly reduce the depressive-like behavior caused by TBI + HB ( $p>0.05 \mathrm{TBI}+\mathrm{Veh}+\mathrm{HB}$ vs. $\mathrm{TBI}+\mathrm{CR} 8+\mathrm{HB})$.
CR8 treatment reduced lesion volume induced by hypobaria exposure following TBI

TBI-induced lesion volume was measured by unbiased stereological techniques (Fig. 11). Histological assessment showed that CR8 treatment $\left(0.71 \pm 0.17 \mathrm{~mm}^{3}, n=5\right)$ resulted in a significant reduction in lesion size after injury as compared with TBI + Veh + HB $\left(2.8 \pm 0.74 \mathrm{~mm}^{3} ; n=5 ; P<0.05\right)$.

Loss of hippocampal neurons and cell cycle inhibition following TBI/HB

It is well known the TBI causes hippocampal neuronal loss [7-15]. In our previous study, we have shown that 

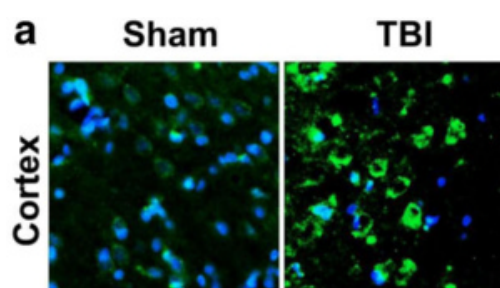

\section{$\mathrm{TBI}+\mathrm{HB} \quad \mathrm{TBI}+\mathrm{HB}+\mathrm{CR} 8$}
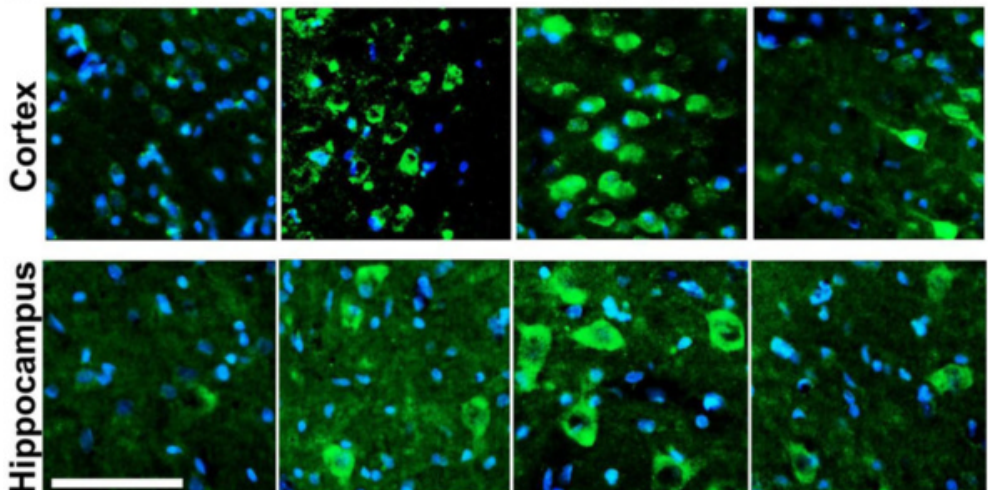

b

Cerebral cortex
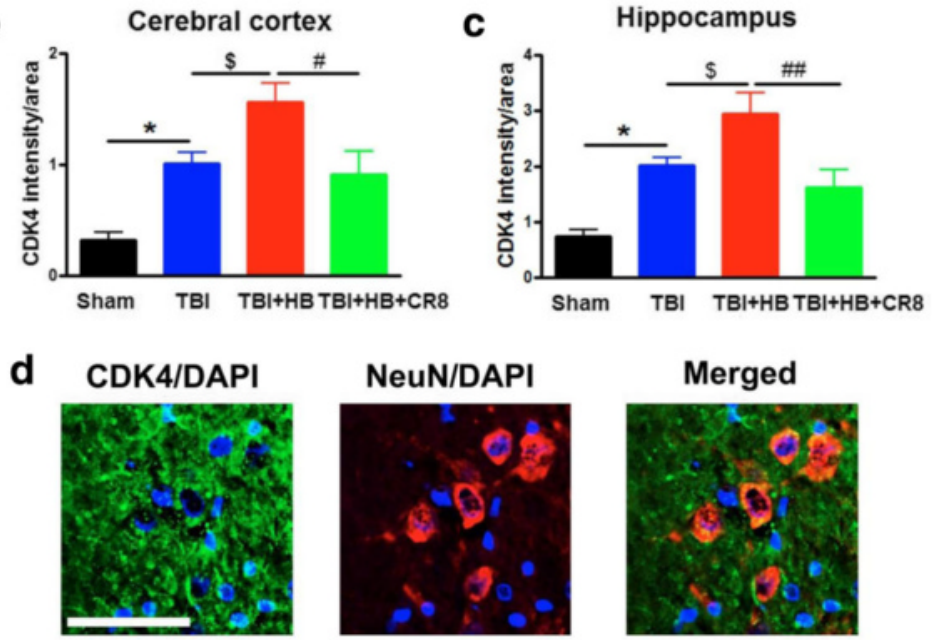

Fig. 5 Hypobaria exposure upregulates the expression of CDK4 in the ipsilateral cortex and hippocampus at 30 days after TBI. a Representative immunofluorescent staining for CDK4 (green) and DAPI (blue). b, c Quantification of pixel intensity for CDK4 revealed significant increases in the $\mathrm{TBI}+$ Veh + HB group in contrast to the TBI-alone tissue. A significant decrease of CDK4 expression was observed in the CR8 treatment group in comparison to the TBI/Neh/HB group. $N=4$ (sham), 6 (TBI), 6 (TBI/Neh/HB), 6 (TBI/CR8/HB). ${ }^{*} p<0.05$, TBI vs. sham injury; ${ }^{\$} p<0.05, \mathrm{TBI} / \mathrm{CR} 8 / \mathrm{HB}$ vs. TBl; $\# p<0.05$, \#\#\# $p<0.001, \mathrm{TBI} / \mathrm{HB} / \mathrm{CR} 8 \mathrm{vs}$. TBINeh/HB. $\mathbf{d}$ Some of the CDK4 ${ }^{+}$cells (green) in the injured cortex were co-labeled with NeuN-expressing neurons (red; DAPI, blue). Scale bar $=50 \mu \mathrm{m}$ in a and $25 \mu \mathrm{m}$ in $\mathbf{d}$

TBI + HB further increases hippocampal neuronal loss at 30 days in comparison to TBI alone [5]. Here, we evaluated whether improvements in cognitive memory function following CR8 treatment were associated with increased hippocampal neuronal survival and total neuronal cell numbers in the ipsilateral hippocampus at post-HB day 30 (Fig. 12). The CR8-treated TBI/HB group showed a significant increase in the total number of surviving hippocampal neurons and number of surviving neurons in the hippocampal DG region compared to the TBI + vehicle + HB group $(p<0.05)$.

\section{Discussion}

Only two prior experimental studies have evaluated the effects of hypobaria following rodent TBI. We recently reported that hypobaria during simulated $\mathrm{AE}$ in a rat TBI model, even with oxygen levels maintained in the normal physiological range, worsens cognitive outcome and increases progressive delayed neurodegeneration and associated chronic inflammatory responses [5]. The other study showed that hypobaric exposure increased cytokine levels acutely after mouse TBI, but that group did not control for the hypoxic effects of hypobaria [6]. The present study is the first to evaluate treatment to limit the negative consequences of post-traumatic hypobaria in an animal model that simulates AE following TBI. Treatment with the CDK inhibitor CR8 reduced hypobaric-induced increases in CCA, post-traumatic microglial activation, and neurodegeneration.

CCA in the brain has been well demonstrated experimentally in models of TBI [11-15], spinal cord injury [21, 24-29], stroke [30, 31], and Alzheimer's disease (AD) [32-35]; it has also been reported in clinical AD [36, 37]. Both neurons and glial cells show increased expression after CNS injury, and such changes may persist for weeks to months [8-10]. Chronic proliferation/ 
a

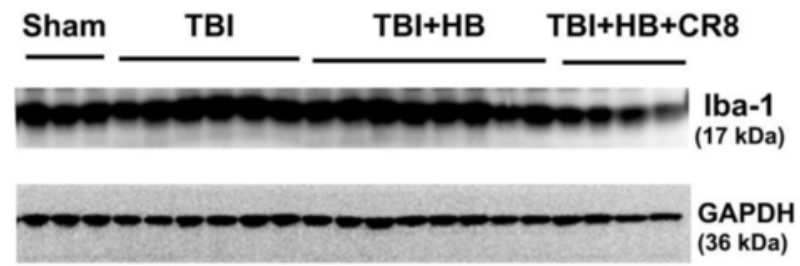

b

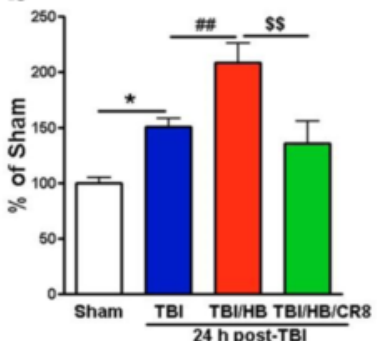

C

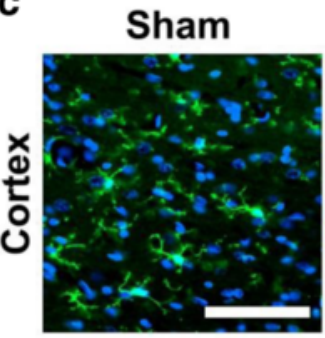

TBI

$\mathrm{TBI}+\mathrm{HB}$

$\mathrm{TBI}+\mathrm{HB}+\mathrm{CR} 8$
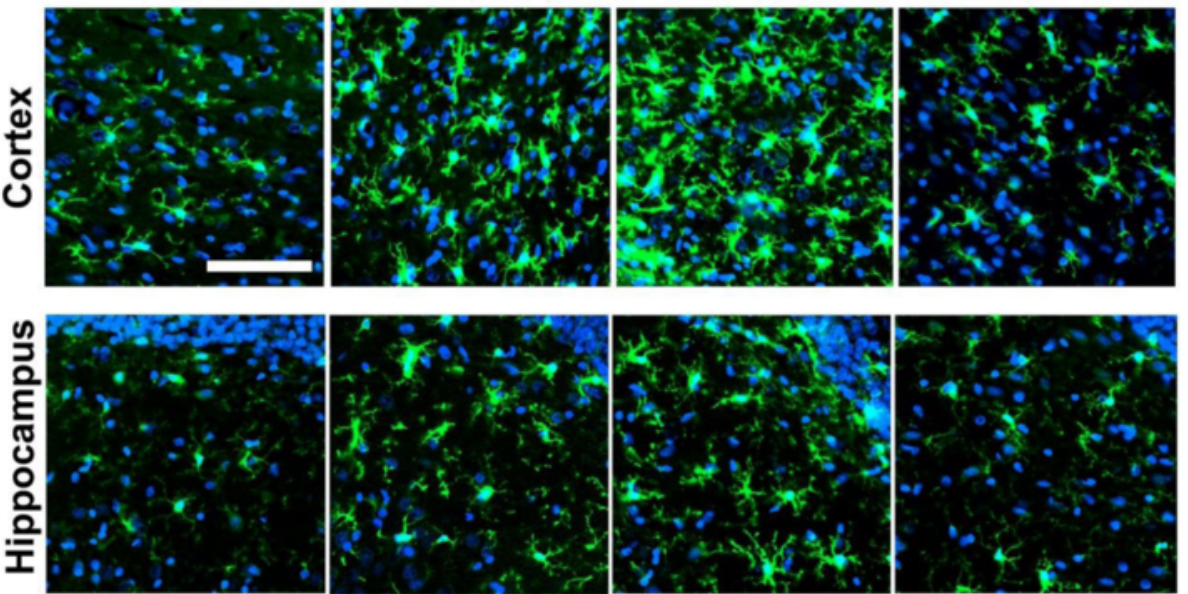

d

Cerebral cortex

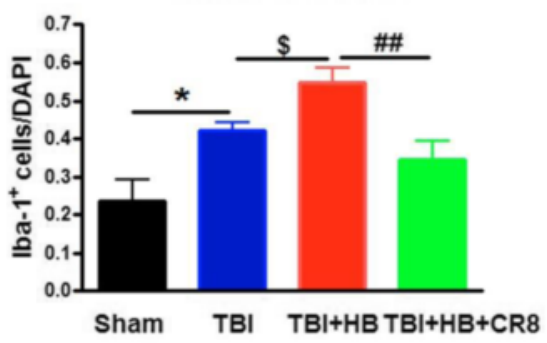

e
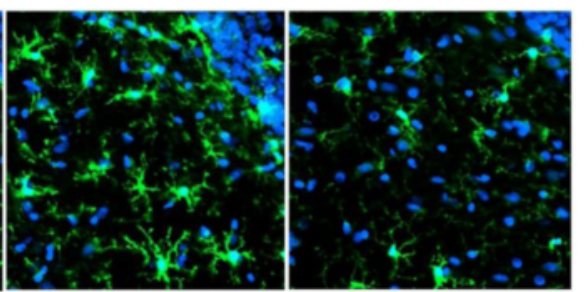

Hippocampus

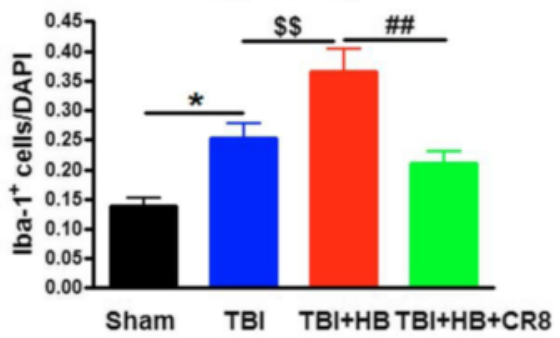

Fig. 6 Cell cycle inhibition reduces protein expression of microglial/macrophages marker Iba-1 induced by hypobaria exposure after TBI. a Representative immunoblots for Iba-1 and the loading control (GAPDH). b Quantification of the expression levels of Iba-1 protein revealed significant increases in the TBI + Veh $+\mathrm{HB}$ group in contrast to the TBI-alone group in the ipsilateral cortex at day 1 after TBI. A significant decrease of lba-1 expression was observed in the CR8 treatment group in comparison to the TBINeh/HB group. $N=7$ (sham), 9 (TBI), 10 (TBI/Neh/HB), 7 (TBI/CR8/HB). * $p<0.05$, TBI vs. sham injury; ${ }^{\# \# ~} p<0.01$, $\mathrm{TBI} / \mathrm{Neh} / \mathrm{HB}$ vs. TBI no HB; ${ }^{\$ \$} p<0.01, \mathrm{TBI} / \mathrm{CR} 8 / \mathrm{HB}$ vs. TBINeh/HB. c Representative immunofluorescent staining for Iba-1 (green) at 30 days post-injury and DAPI (blue). $\mathbf{d}$, e Quantification of Iba- $1^{+}$cells revealed significant increases in the TBI + Veh + HB group in contrast to the TBl-alone group. A significant decrease of Iba- $1^{+}$cells was observed in the CR8 treatment group in comparison to the TBI/Neh/HB group. $N=4$ (sham), 6 (TBI), 6 (TBI/Neh/HB), 6 (TBI/CR8/HB). ${ }^{*} p<0.05$, TBI vs. sham injury; ${ }^{\$} p<0.05,{ }^{\$ \$} p<0.01$, TBINeh/HB vs. TBI; ${ }^{\# \#} p<0.001, \mathrm{TBI} / \mathrm{CR} 8 / \mathrm{HB}$ vs. TBINeh/HB. Scale bar $=50 \mu \mathrm{m}$

activation of astrocytes and microglia resulting from CCA may contribute to secondary injury and limit neurorestoration $[15,18]$. Reactive astrocytes are involved in the formation of the glial scar, which can inhibit axonal regeneration [38]. Activated microglia can produce proinflammatory cytokines and ROS, leading to neuronal degeneration [18]. Adult differentiated post-mitotic neurons can re-enter the cell cycle; however, such re-entry is associated with caspase-mediated neuronal apoptosis [11, 39-41].

CCA is an intricate and highly regulated process [8-10]. Through each phase in the cycle, there is a systematic progression of synthesis and degradation of phase-specific cyclin proteins. Cyclins bind and activate $\mathrm{Ser} / \mathrm{Thr}$ kinases known as cyclin-dependent kinases (CDKs), which in turn phosphorylate additional 

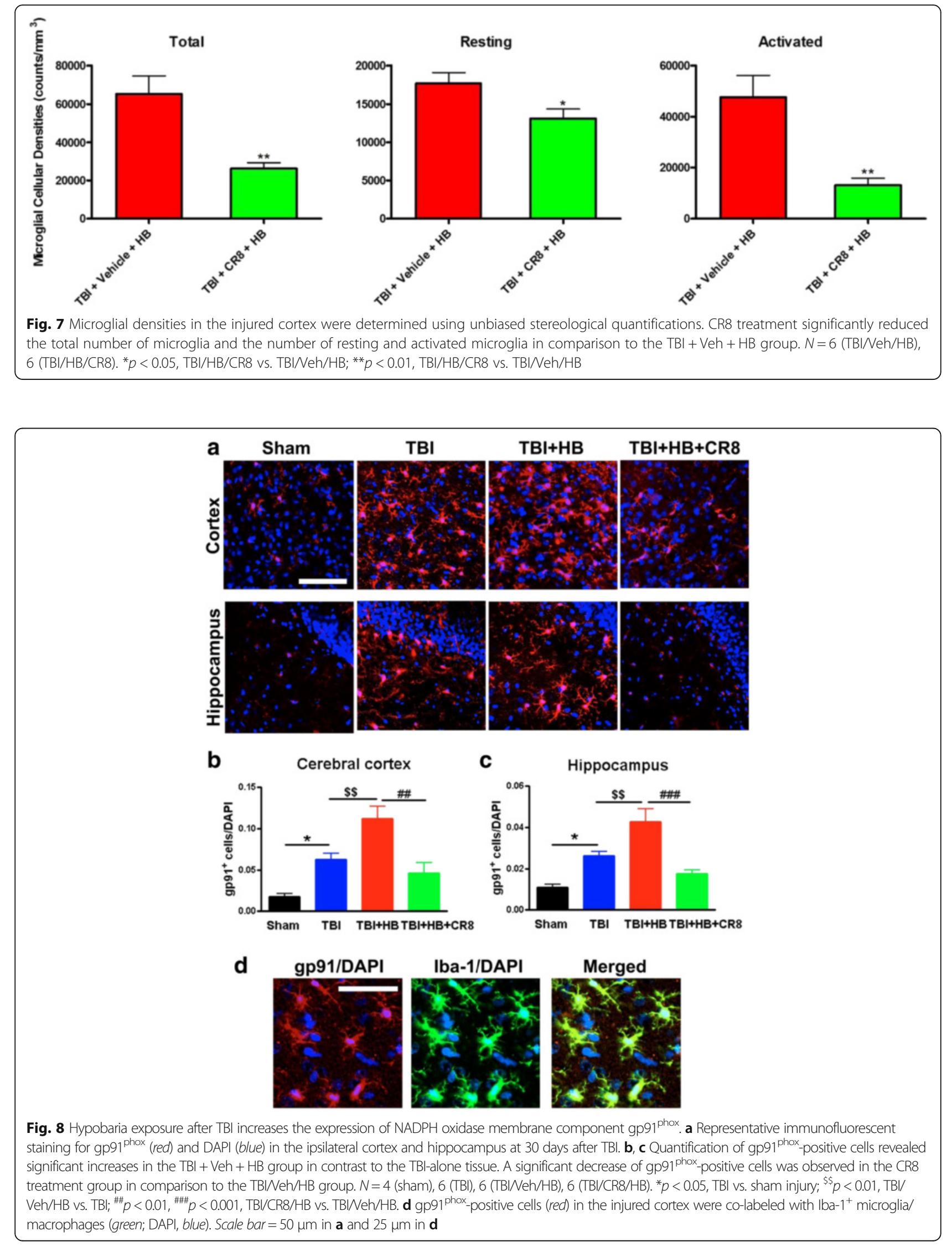

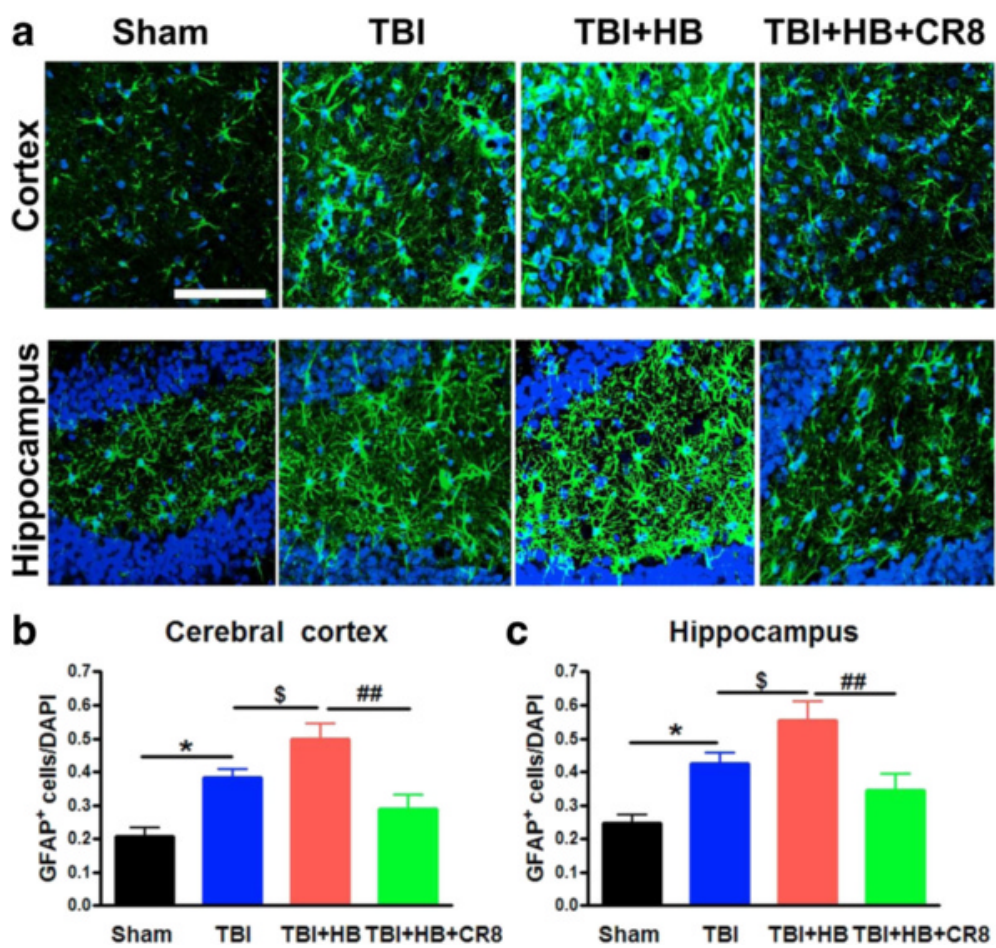

Fig. 9 Cell cycle inhibition reduces protein expression of astrocytes marker GFAP induced by hypobaria exposure following TBI. a Representative immunofluorescent staining for GFAP (green) and DAPI (blue). b, c Quantification of GFAP ${ }^{+}$cells revealed significant increases in the TBI + Veh + HB group in contrast to the TBI-alone tissue. A significant decrease of GFAP ${ }^{+}$cells was observed in the CR8 treatment group in comparison to

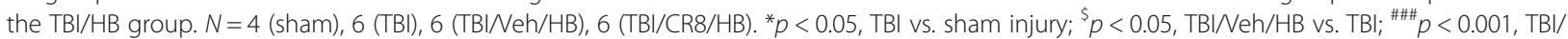
$\mathrm{CR} 8 / \mathrm{HB}$ vs. TBI/Neh/HB. Scale bar $=50 \mu \mathrm{m}$

substrates that promote transcription of other cyclins and progression through the cycle. During the first phase of the cell cycle, Gap 1 (G1), levels of cyclin D increase. Cyclin D binds to CDK4, promoting phosphorylation of the retinoblastoma $(\mathrm{Rb})$ family of proteins. Phosphorylated $\mathrm{Rb}$ proteins dissociate from E2F transcription factors, which translocate to the cell nucleus and induce the transcription of other cyclins. Proteins involved in the G1 phase of the cell cycle have been identified as part of a pro-apoptotic pathway in post-mitotic neurons $[9,10]$. Activation of CDK4 by cyclin D1 has been found to be necessary for apoptosis in neurons that re-enter the cell cycle $[39,41]$. Furthermore, reduction of CDK4 expression is protective against apoptosis in primary neuronal cell cultures and ablation of the cyclin D1 gene limits lesion development and improves functional outcomes following TBI [42, 43].

Treatment with cell cycle inhibitors increases neuronal survival and reduces glial proliferation/activation in several CNS injury models, including rat and mouse TBI models [11-15, 21, 25-29]. After fluid percussion injury, administration of the pan-CDK inhibitor flavopiridol reduced cyclin D1 expression in neurons and glia in the cortex and hippocampus; treatment also decreased neuronal cell death, lesion volume, astroglial scar formation, and microglial activation and improved motor and cognitive recovery [11]. Central administration of another CDK inhibitor, roscovitine, $30 \mathrm{~min}$ after fluid percussion-induced brain injury, significantly decreased lesion volume, as well as improving motor and cognitive recovery [12]. Roscovitine also attenuated neuronal death and inhibited activation of CCA in neurons, as well as decreasing microglial activation and astrogliosis. In primary cortical microglial and neuronal cultures, roscovitine treatment attenuated neuronal cell death and decreased microglial activation as well as microglialdependent neurotoxicity [12]. Central administration of CR8, a selective and highly potent CDK inhibitor structurally related to roscovitine, attenuated CCA pathways, and reduced post-traumatic apoptotic cell death at $24 \mathrm{~h}$ post-TBI $[14,15]$. Administration of CR8 at $3 \mathrm{~h}$ postinjury limited CCA, reduced microglial activation and lesion volume, and improved behavioral outcomes in both mouse and rat models of experimental TBI $[14,15]$.

In the present study, the cell cycle markers cyclin D1, PCNA, and CDK4 were significantly increased following TBI/HB at $24 \mathrm{~h}$ and 30 days compared to TBI alone. It is well known that the upregulation of cell cycle proteins occurs in both post-mitotic cells (neurons, mature 


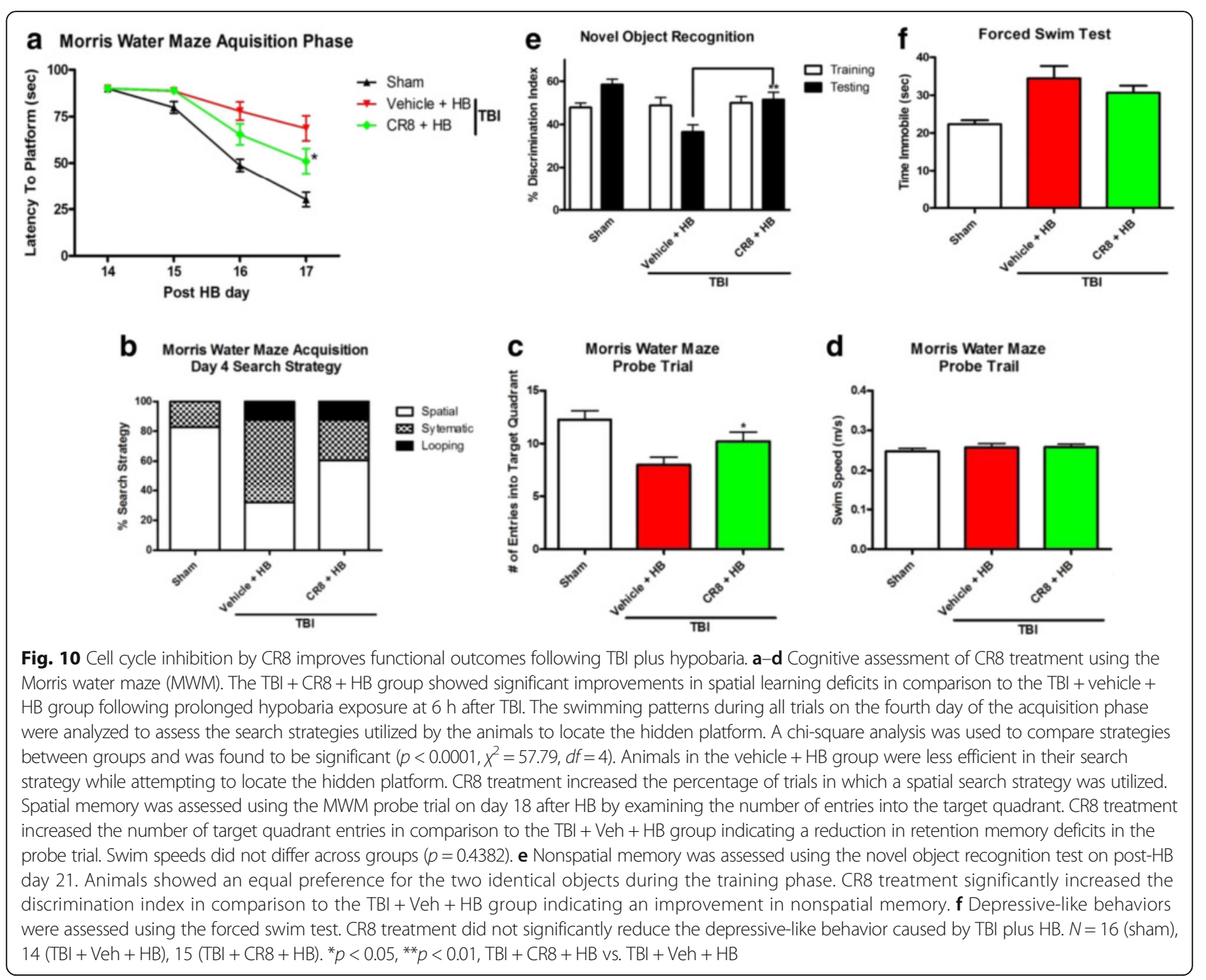

oligodendroglia) and proliferating cell types including microglia and astrocytes after TBI. In addition to neurons, microglia, and astrocytes that are predominant cell types in the brain, mature oligodendrocytes also undergo apoptotic cell death at acute phase post-injury (e.g., d1, d3 post-injury). We demonstrate changes across brain cell types [11]. We have shown that CCA inhibitors (flavopiridol, CR8) significantly decrease oligodendroglial apoptosis in the injured spinal cord at 1 day post-injury $[24,26]$. Whether or not hypobaria (HB) in TBI animals increases CCA expression in oligodendrocytes is intriguing, that merits further research. In addition, expression levels of the microglial/macrophage markers Iba-1 and $\mathrm{gp} 91^{\mathrm{phox}}$ and the astroglial marker GFAP were significantly higher in the TBI/HB group than in TBI animals without $\mathrm{HB}$. Treatment with $\mathrm{CR} 8$ prior to $\mathrm{HB}$ exposure significantly reduced the expression of cell cycle, microglia/macrophage, and astrocytes markers in comparison to the vehicle-treated TBI/HB group. CR8 significantly reduced deficits in spatial learning and retention memory function caused by $\mathrm{HB}$ exposure plus TBI, as reflected by the MWM and novel object recognition tests. However, CR8 treatment did not reduce depressive-like behavioral changes associated with TBI + $\mathrm{HB}$ exposure. Chronic microglial activation at 30 days after TBI/HB was also attenuated by CR8 treatment. There was no significant difference between TBI/HB/ CR8 and TBI-alone groups in any of the assays performed. Although CR8 treatment at current dose and timing of administration did not completely reverse CDK4 signaling in the injured cortex $(p<0.05, \mathrm{TBI} / \mathrm{HB} /$ CR8 vs. sham) at both acute and chronic time points post-injury, the other CCA components tested (cyclin D1, PCNA) as well as markers for inflammation (Iba-1, gp91) and astrogliosis (GFAP) were significantly reduced by CR8 treatment to close to a basal level. There was no significant difference between TBI/HB/CR8 and sham groups in the ipsilateral cortex and hippocampus at day 1 or days 28 post-injury. Thus, CR8-mediated reduction of CCA and neuroinflammation are associated with 

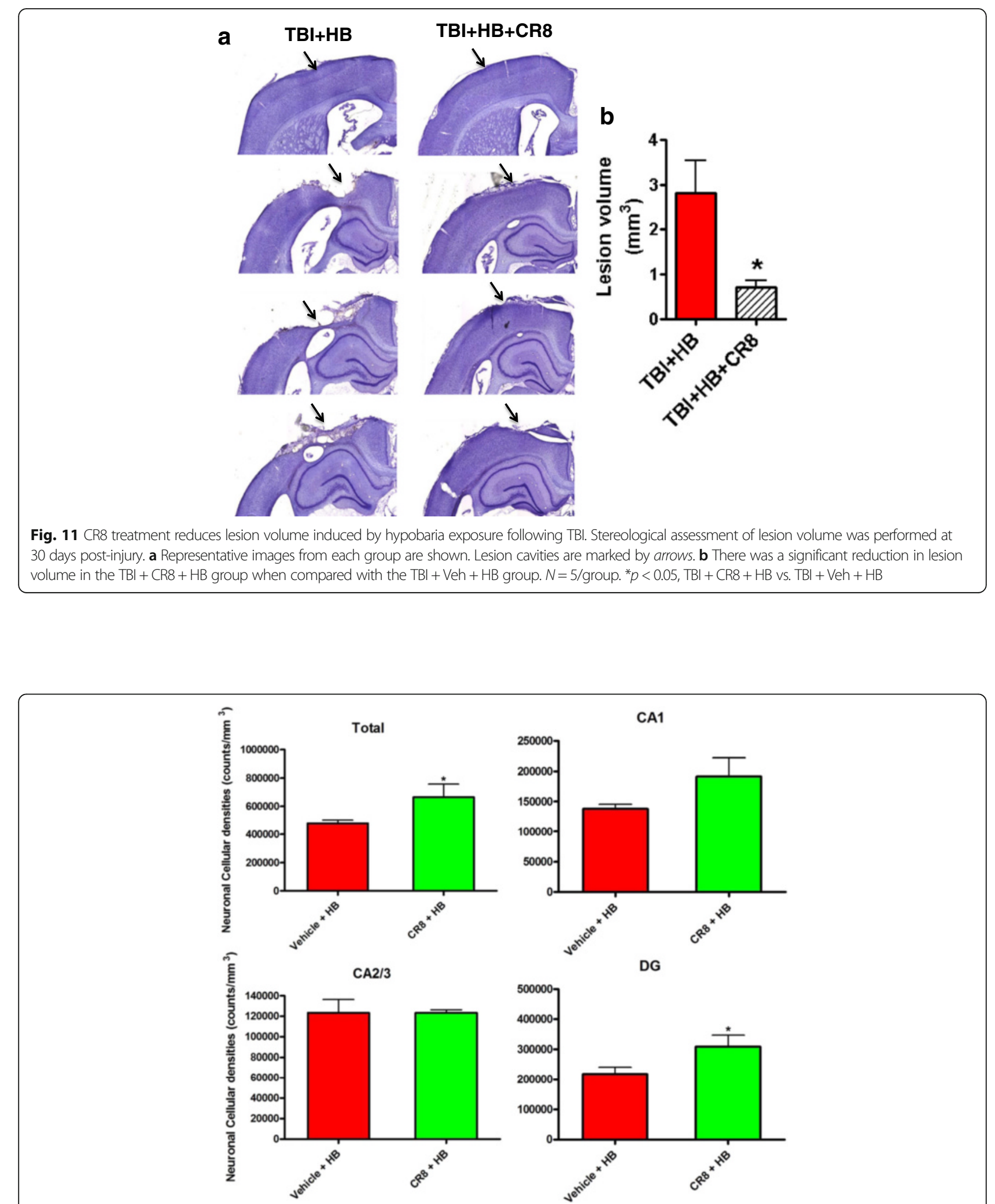

Fig. 12 Effect of CR8 treatment following TBI plus hypobaria on neuronal cell loss in the hippocampus. Total neuronal cell numbers in the hippocampus ipsilateral to the site of injury were evaluated at 30 days post-injury. Unbiased stereological quantifications show that treatment with CR8 increased total neuronal density in the hippocampus and in the DG subregion compared with the TBI + Veh + HB group. $N=5$ (TBI/Veh + HB), $5(\mathrm{TBI} / \mathrm{CR} 8 / \mathrm{HB}) .{ }^{*} p<0.05 \mathrm{TBI}+\mathrm{CR} 8+\mathrm{HB}$ vs. TBI + Veh $+\mathrm{HB}$ 
improved functional outcome after $\mathrm{HB}$ exposure in TBI animals. In the present study, CR8 dose and timing of administration were based on previous studies using this compound in experimental animal models of TBI-which have shown neuroprotection by limiting microglial activation, astrocytosis, and neuronal loss. However, optimizing CR8 treatment condition is intriguing which merits further research. Collectively, these results suggest that increases in CCA activation caused by HB exposure following TBI result in neuronal cell death and neurotoxic microglial activation, which likely contribute to the exacerbation of cognitive dysfunction. CR8 treatment attenuated CCA and neuroinflammatory responses that were intensified by $\mathrm{HB}$ exposure following TBI. Given that changes in $\mathrm{AE}$ procedures and timing may not be possible because of the need to rapidly transport critically ill patients to definitive treatment sites, use of cell cycle inhibitors-previously examined in late human phase cancer treatment studies-should be explored as a way of limiting the negative consequences of $\mathrm{AE}$ in TBI patients.

\section{Conclusions}

Wartime casualties with traumatic brain injuries may be exposed to prolonged periods of hypobaria during aeromedical evacuation. As hypobaria exposure following TBI has been shown to worsen pathophysiological and cognitive outcomes, treatments to mitigate these effects must be identified. This study evaluated the effects of prolonged hypobaria in rats subjected to traumatic brain injury on cell cycle and neuroinflammatory pathways and examined the ability of the cell cycle inhibitor CR8 to alleviate the associated effects. Hypobaria exposure following TBI significantly increased markers of cell cycle activation and microglial activation. These changes were limited by treatment with the cell cycle inhibitor CR8 at $3 \mathrm{~h}$ post-injury. CR8 treatment also significantly reduced cognitive deficits associated with hypobaria exposure following injury.

\section{Abbreviations \\ AD: Alzheimer's disease; AE: aeromedical evacuation; CA1, CA2, CA3: cornus ammonis 1, 2, 3; CCA: cell cycle activation; D.I.: discrimination index; DAPI: 4',6-diamidino-2-phenylindole; DG: dentate gyrus; FP: fluid percussion; HB: hypobaria; HRP: horseradish peroxidase; Iba-1: ionized calcium-binding adapter molecule 1; MWM: Morris water maze; PCNA: proliferating cell nuclear antigen; Rb: retinoblastoma; RIPA: radioimmunoprecipitation assay; ROS: reactive oxygen species; SDS: sodium dodecyl sulfate; TBI: traumatic brain injury}

\section{Acknowledgements}

This material is based on a research sponsored by the 711 HPW/XPT under Cooperative Agreement number FA8650-11-2-6D04. The US Government is authorized to reproduce and distribute reprints for governmental purposes notwithstanding any copyright notation thereon. The authors thank Shuxin Zhao and Katherine Cardiff for their expert technical assistance and Dr. Hegang Chen for expert statistical consultation.

The views expressed in this article are those of the authors and do not necessarily reflect the official policy or position of the Air Force, the Department of Defense, or the US Government.

\section{Funding}

This study was supported by the $711 \mathrm{HPW} / \mathrm{XPT}$ under Cooperative Agreement number FA8650-11-2-6D04. The funder had no role in the study design, data collection, and analysis, decision to publish, or preparation of the manuscript.

Availability of data and materials

Data supporting the conclusions of this article are presented in the manuscript.

\section{Authors' contributions}

JWS contributed to the design of the studies, analysis, and interpretation of data; carried out the TBI surgery and behavioral test; and wrote and revised the manuscript. JW contributed to the design of the studies; performed the WB, data analysis, and interpretation; and wrote and revised the manuscript. JM, AK, MH, and SK performed the behavioral tests, IHC, data analysis, and tissue processing. AlF conceived the research, participated in interpretation of the data, and revised the manuscript. RF assisted with the grant proposal supporting this work, as well as in the review and editing. All authors read and approved the final manuscript.

\section{Competing interests}

Dr. Skovira was a participant in the Department of Defense Science, Mathematics and Research for Transformation (SMART) Scholarship for Service Program, and this manuscript represents a portion of his work in the completion of a Ph.D. from the University of Maryland, Baltimore. The other authors declare that they have no competing interests.

\section{Consent for publication}

Not applicable.

\section{Ethics approval and consent to participate}

All procedures and animal experiments were carried out in accordance with protocols approved by the Animal Care and Use Committee at the University of Maryland (permission code 0415006) and the United States Air Force. All experimental protocols requiring biosafety were approved by the Institutional Biosafety Committee (IBC) of the University of Maryland School of Medicine.

\section{Author details}

${ }^{1}$ Department of Anesthesiology and Center for Shock, Trauma and Anesthesiology Research (STAR), University of Maryland School of Medicine, Baltimore, MD 21201, USA. ${ }^{2}$ Research Division Pharmacology Branch, United States Army Medical Research Institute of Chemical Defense, Aberdeen Proving Ground, Aberdeen, MD 21010, USA. ${ }^{3}$ Program in Trauma, Center for the Sustainment of Trauma and Readiness Skills (C-STARS), University of Maryland School of Medicine, Baltimore, MD 21201, USA.

Received: 11 August 2016 Accepted: 24 November 2016

Published online: 01 December 2016

\section{References}

1. Faul M, Xu L, Waid MM, Coronado VG. Traumatic brain injury in the United States: emergency department visits. Hospitalizations and deaths 20022006. Atlanta: Centers for Disease Control and Prevention, National Center for Injury Prevention and Control; 2010.

2. Defense and Veterans Brain Injury Center. DOD TBI worldwide numbers since 2000. In: DOD TBI Worldwide Numbers. 2016. http://dvbic.dcoe.mil/ sites/default/files/uploads/Worldwide\%20Totals\%202000-2014Q1.pdf. Accessed 15 June 2016

3. Reno J. Military aeromedical evacuation, with special emphasis on craniospinal trauma. Neurosurg Focus. 2010;28(5):E12.

4. Fang R, Dorlac G, Allan P, Dorlac W. Intercontinental aeromedical evacuation of patients with traumatic brain injuries during operations Iraqi Freedom and Enduring Freedom. Neurosurg Focus. 2010;28(5):E11.

5. Skovira JW, Kabadi SV, Wu J, Zhao Z, DuBose J, Rosenthal R, Fiskum G, Faden Al. Simulated aeromedical evacuation exacerbates experimental brain injury. J Neurotrauma. 2016. doi:10.1089/neu.2015.4189.

6. Goodman MD, Makley AT, Huber NL, Clarke CN, Friend LA, Schuster RM, Bailey SR, Barnes SL, Dorlac WC, Johannigman JA, Lentsch AB, Pritts TA. Hypobaric hypoxia exacerbates the neuroinflammatory response to traumatic brain injury. J Surg Res. 2011;165(1):30-7.

7. Faden Al. Microglial activation and traumatic brain injury. Ann Neurol. 2011; 70(3):345. 
8. Cernak I, Stoica B, Byrnes KR, Di Giovanni S, Faden Al. Role of the cell cycle in the pathobiology of central nervous system trauma. Cell Cycle. 2005:4(9): 1286-93.

9. Byrnes KR, Faden Al. Role of cell cycle proteins in CNS injury. Neurochem Res. 2007;32(10):1799-807.

10. Stoica BA, Byrnes KR, Faden Al. Cell cycle activation and CNS injury. Neurotox Res. 2009;16(3):221-37.

11. Di Giovanni S, Movseyan V, Ahmed F, Cernak I, Schinelli S, Stoica B. Cell cycle inhibition provides neuroprotection and reduces glial proliferation and scar formation after traumatic brain injury. PNAS. 2005;102(23):8333-8.

12. Hilton GD, Stoica BA, Byrnes KR, Faden Al. Roscovitine reduces neuronal loss, glial activation, and neurologic deficits after brain trauma. J Cereb Blood Flow Metab. 2008;11:1845-59.

13. Kabadi SV, Stoica BA, Byrnes KR, Hanscom M, Loane DJ, Faden Al. Selective CDK inhibitor limits neuroinflammation and progressive neurodegeneration after brain trauma. J Cereb Blood Flow Metab. 2012;32(1):137-49.

14. Kabadi SV, Stoica BA, Hanscom M, Loane DJ, Kharebava G, Murray li MG, Cabatbat RM, Faden Al. CR8, a selective and potent CDK inhibitor, provides neuroprotection in experimental traumatic brain injury. Neurotherapeutics. 2012;9(2):405-21.

15. Kabadi SV, Stoica BA, Loane DJ, Luo T, Faden Al. CR8, a novel inhibitor of CDK, limits microglial activation, astrocytosis, neuronal loss, and neurologic dysfunction after experimental traumatic brain injury. J Cereb Blood Flow Metab. 2014;34(3):502-13.

16. Dardiotis E, Karanikas V, Paterakis K, Fountas K, Hadjigeorgiou GM. Traumatic brain injury and inflammation: emerging role of innate and adaptive immunity. In: Agrawal A, editor. Brain injury-pathogenesis, monitoring, recovery and management. ISBN: 978-953-51-0265-6, InTech, March 2012

17. Colton C. Heterogeneity of microglial activation in the innate immune response in the brain. J Neuroimmume Pharmacol. 2009;4:399-418.

18. Loane DJ, Byrnes KR. Role of microglia in neurotrauma. Neurotherapeutics. 2010;7(4):366-77.

19. Ramlackhansingh AF, Brooks DJ, Greenwood RJ, Bose SK, Turkheimer FE, Kinnunen KM, Gentleman S, Heckemann RA, Gunanayagam K, Gelosa G. Sharp inflammation after trauma: microglial activation and traumatic brain injury. J Ann Neurol. 2011;70(3):374-83.

20. Kabadi SV, Hilton GD, Stoica BA, Zapple DN, Faden Al. Fluid-percussioninduced traumatic brain injury model in rats. Nat Protoc. 2010;5(9):1552-63.

21. Wu J, Zhao Z, Sabirzhanov B, Stoica BA, Kumar A, Luo T, Skovira J, Faden Al. Spinal cord injury causes brain inflammation associated with cognitive and affective changes: role of cell cycle pathways. J Neurosci. 2014;34(33):10989-1006.

22. Sarkara C, Zhaoa Z, Aungst S, Sabirzhanova B, Faden Al, Lipinski MM. Impaired autophagy flux is associated with neuronal cell death after traumatic brain injury. Autophagy. 2014;10(12):2208-22.

23. Liu S, Sarkar C, Dinizo M, Faden Al, Koh EY, Lipinski MM, Wu J. Disrupted autophagy after spinal cord injury is associated with ER stress and neuronal cell death. Cell Death Dis. 2015;6(1):e1582. doi:10.1038/cddis.2014.527.

24. Byrnes KR, Stoica BA, Fricke S, Di Giovanni S, Faden Al. Cell cycle activation contributes to post-mitotic cell death and secondary damage after spinal cord injury. Brain. 2007;130(Pt 11):2977-92.

25. Tian DS, Xie MJ, Yu ZY, Zhang Q, Wang YH, Chen B, Chen C, Wang W. Cell cycle inhibition attenuates microglia induced inflammatory response and alleviates neuronal cell death after spinal cord injury in rats. Brain Res. 2007; 1135(1):177-85.

26. Wu J, Stoica BA, Dinizo M, Pajoohesh-Ganji A, Piao C, Faden Al. Delayed cell cycle pathway modulation facilitates recovery after spinal cord injury. Cell Cycle. 2012;11(9):1782-95. doi:10.4161/cc.20153.

27. Wu J, Pajoohesh-Ganji A, Stoica BA, Dinizo M, Guanciale K, Faden Al. Delayed expression of cell cycle proteins contributes to astroglial scar formation and chronic inflammation after rat spinal cord contusion. J Neuroinflammation. 2012;9:169. doi:10.1186/1742-2094-9-169.

28. Wu J, Stoica BA, Luo T, Sabirzhanov B, Zhao Z, Guanciale K, Nayar SK, Foss CA, Pomper MG, Faden Al. Isolated spinal cord contusion in rats induces chronic brain neuroinflammation, neurodegeneration, and cognitive impairment. Involvement of cell cycle activation. Cell Cycle. 2014;13(15): 2446-58. doi:10.4161/cc.29420.

29. Wu J, Zhao Z, Zhu X, Renn CL, Dorsey SG, Faden Al. Cell cycle inhibition limits development and maintenance of neuropathic pain following spinal cord injury. Pain. 2016;157(2):488-503. doi:10.1097/j.pain.0000000000000393.

30. Rashidian J, lyirhiaro GO, Park DS. Cell cycle machinery and stroke. Biochim Biophys Acta. 2007;1772(4):484-93.
31. Osuga H, Osuga S, Wang F, Fetni R, Hogan MJ, Slack RS, Hakim AM, Ikeda JE, Park DS. Cyclin-dependent kinases as a therapeutic target for stroke. Proc Natl Acad Sci U S A. 2000;97(18):10254-9.

32. Sanphui P, Pramanik SK, Chatterjee N, Moorthi P, Banerji B, Biswas SC Efficacy of cyclin dependent kinase 4 inhibitors as potent neuroprotective agents against insults relevant to Alzheimer's disease. PLoS One. 2013;8(11): e78842. doi:10.1371/journal.pone.0078842.

33. Seward ME, Swanson E, Norambuena A, Reimann A, Cochran JN, Li R, Roberson ED, Bloom GS. Amyloid- $\beta$ signals through tau to drive ectopic neuronal cell cycle re-entry in Alzheimer's disease. J Cell Sci. 2013;126(Pt 5): 1278-86. doi:10.1242/jcs.1125880.

34. Arendt T. Cell cycle activation and aneuploid neurons in Alzheimer's disease. Mol Neurobiol. 2012;46(1):125-35. doi:10.1007/s12035-012-8262-0.

35. Neve RL, McPhie DL. The cell cycle as a therapeutic target for Alzheimer's disease. Pharmacol Ther. 2006:111(1):99-113.

36. Katsel P, Tan W, Fam P, Purohit DP, Haroutunian V. Cell cycle checkpoint abnormalities during dementia: a plausible association with the loss of protection against oxidative stress in Alzheimer's disease. PLoS One. 2013; 8(7):e68361. doi:10.1371/journal.pone.0068361.

37. Kim H, Kwon Y-A, Ahn IS, Kim S, Kim S, Ahn Jo S, Kim DK. Overexpression of cell cycle proteins of peripheral lymphocytes in patients with Alzheimer's disease. Psychiatry Investig. 2016;13(1):127-34.

38. Silver J, Miller JH. Regeneration beyond the glial scar. Nat Rev Neurosci. 2004;5:146-56

39. Kranenburg O, van der Eb AJ, Zantema A. Cyclin D1 is an essential mediator of apoptotic neuronal cell death. EMBO J. 1996;15:46-54.

40. Herrup K, Yang Y. Cell cycle regulation in the postmitotic neuron: oxymoron or new biology? Nat Rev Neurosci. 2007:8(5):368-78.

41. Shan B, Lee WH. Deregulated expression of E2F-1 induces S-phase entry and leads to apoptosis. Mol Cell Biol. 1994;14(12):8166-73.

42. Rashidian J, lyirhiaro G, Aleyasin H, Rios M, Vincent I, Callaghan S, Bland RJ, Slack RS, During MJ, Park DS. Multiple cyclin-dependent kinases signals are critical mediators of ischemia/hypoxic neuronal death in vitro and in vivo. Proc Natl Acad Sci U S A. 2005;102(39):14080-5.

43. Kabadi SV, Stoica BA, Loane DJ, Byrnes KR, Hanscom M, Cabatbat RM, Tan MT, Faden Al. Cyclin D1 gene ablation confers neuroprotection in traumatic brain injury. J Neurotrauma. 2012;29(5):813-27.

\section{Submit your next manuscript to BioMed Central and we will help you at every step:}

- We accept pre-submission inquiries

- Our selector tool helps you to find the most relevant journal

- We provide round the clock customer support

- Convenient online submission

- Thorough peer review

- Inclusion in PubMed and all major indexing services

- Maximum visibility for your research

Submit your manuscript at www.biomedcentral.com/submit 